\title{
Response
}

\section{Impact of HbA1c Criterion on the Detection of Subjects with Increased Risk for Diabetes among Health Check-Up Recipients in Korea (Diabetes Metab J 2012;36:151-6)}

Hong-Kyu Kim, Sung-Jin Bae, Jaewon Choe

Health Screening and Promotion Center, Asan Medical Center, Seoul, Korea

Thank you for your interest and comments on our study, "Impact of HbAlc criterion on the detection of subjects with increased risk for diabetes among health check-up recipients in Korea" published in Diabetes \& Metabolism Journal 2012;36; 151-6.

Regarding the standardization of A1c value, we measured Alc by ion-exchange high-performance liquid chromatography using an automated analyzer (Variant II ${ }^{\mathrm{TM}}$; Bio-Rad Laboratories, Hercules, CA, USA), which has already been aligned to the Diabetes Control and Complications Trial (DCCT) reference standard and certified by the National Glycohemoglobin Standardization Program [1,2].

\section{CONFLICTS OF INTEREST}

No potential conflict of interest relevant to this article was reported.

\section{REFERENCES}

1. American Diabetes Association. Diagnosis and classification of diabetes mellitus. Diabetes Care 2011;34 Suppl 1:S62-9.

2. National Glycohemoglobin Standardization Program: List of NGSP certified methods. Available from: http://www.ngsp. org/docs/methods.pdf (updated 2012 Jun 1).
Corresponding author: Hong-Kyu Kim

Health Promotion Center, Asan Medical Center, 88 Olympic-ro 43-gil,

Songpa-gu, Seoul 138-736, Korea

E-mail: hkkim0801@amc.seoul.kr
This is an Open Access article distributed under the terms of the Creative Commons At tribution Non-Commercial License (http://creativecommons.org/licenses/by-nc/3.0/) which permits unrestricted non-commercial use, distribution, and reproduction in any medium, provided the original work is properly cited. 